\title{
Bioethics needs a distinct voice if it is to aid science
}

\author{
Neither scientific knowledge nor gut feeling is enough to support decision-making.
}

Sir - Paul Copland in his Correspondence "Science and ethics must not be separated" (Nature 425, 121; 2003) argues that ethics is an integral part of science and therefore the two must not be separated. But I believe that we should distinguish between separation (which is necessary to allow for the development of expertise) and the use of unscientific approaches (which can make communication with scientists impossible).

Scientists should therefore not argue against the establishment of the philosophical discipline of bioethics; rather, they should welcome it. What science should argue for is a 'scientific' rather than a dogmatic approach in the humanities, and specifically in bioethics.

Philosophically, perhaps the biggest achievement of science is the abandonment of dogmatism and the acceptance that all scientific knowledge can potentially be changed by new data and new insights. Similarly, scientists should request from scholars in the humanities that they abandon any “ill-defined 'personal philosophy' and 'gut feeling"” and open themselves to an informed search for the better argument.

It is naive to believe that the views of scientists (especially those directly involved in discoveries) would be more objective than those of expert bioethicists.

The problem with science is that we often do not know the answers for certain. Will stem-cell research develop a cure for Parkinson's disease? Will transgenic crops pose any risk at all? And therefore we can only present data, which then form the basis of non-scientific decisions. There is no reason to assume that scientists would be better equipped to make these decisions than non-scientists.

The fact that bioethics has developed as a discipline distinct from science simply reflects the reality that, unfortunately, most scientists do not have the time to become experts in the philosophy of science and bioethics.

We should therefore not fight the development of a philosophical discipline of bioethics, but should ensure that the approaches the discipline takes are scientific and undogmatic.

Alfons Lawen

Department of Biochemistry and Molecular Biology, Building 13D, School of Biomedical Sciences, Monash University, Victoria 3800, Australia

\section{Bioethics: role of religion cannot be ignored}

Sir - I agree with P. Copland, who wrote in Correspondence ("Science and ethics must not be separated" Nature 425, 121; 2003) that as scientists we are in a "privileged position" to acquire and interpret scientific information and its ethical implications. But with this privilege comes the responsibility to listen carefully to the concerns of the wider community, whether its members understand developmental biology or not. Otherwise, we risk marginalization in the bioethics debate.

As scientists we are clever enough to know that our articulation of scientific ingenuity to non-scientists increases cash flow for biomedical research. To insist, as Copland does, that these same benefactors are unqualified to grapple with complex bioethical issues is incorrect.

Societal ethics cannot be conveniently separated from religion when most members of society derive their ethics from religious sources. Indeed, whether scientists think such sources are important or not is completely irrelevant; the religious contribution to ethical debate cannot simply be ignored.

\section{Stephen J. McSorley}

University of Connecticut Health Center, Department of Medicine, Division of Immunology, 263 Farmington Avenue, Farmington, Connecticut 06030-1319, USA

\section{Unnatural coverage of Chernobyl tragedy}

Sir - Your Books and Arts exhibition review "Unnatural causes" (Nature 425, 347; 2003) described two photographic exhibits at the Tenth International Biennale of Photography in Turin, Italy. These included photographs by the Kiev artist Ilya Chichkan of deformed fetuses that he "borrowed" from mothers living in Kiev during and after Chernobyl. Chichkan removed the fetuses from their jars of formalin, dressed them in jewels and photographed them. The review was accompanied by one of the photos it described.

I understand that Chichkan may have been trying to emphasize the tragedy of Chernobyl. However, I found both the exhibit and your description of it to be gratuitous and tasteless. Rather than seeing a "normal sleeping child", I saw a tragically deformed fetus, killed by the carelessness of men, and perversely dressed up like a doll. Rather than seeing one of the "sleeping princes of Ukrainian legend" in “anachronistic dignity", I saw a poor dead child exploited for media sensationalism. Your coverage of this exhibit is what I would expect from a lurid tabloid, not a pre-eminent science journal. In the future, please remember that although many of Nature's readers are biologists, we are also mothers and fathers, with parents' sensibilities.

\section{Oliver R. W. Pergams}

Department of Conservation Biology, Chicago Zoological Society, Brookfield,

Illinois 60513-1095, USA

\section{India's mission to the Moon is worthwhile}

Sir - Your New Delhi correspondent attributes views to me (Nature 424, 985; 2003) that imply I do not support the Moon mission of the Indian Space Research Organisation (ISRO).

As I had no discussion with your correspondent just before the report was filed, I suspect that it was based on comments I made about a year ago to the effect that "exploration of the Moon should really be an international enterprise, and India, as one of the countries that has the capability to undertake such an exploration, should naturally be a part of that enterprise". This is a view I still hold, and is actually an endorsement of India's joining the enterprise, especially as $15 \%$ of the payload on the Indian satellite to the Moon is available for international collaboration.

Similarly, my belief that exploration of our own planet is of profound importance, should not be interpreted as opposition to the Moon mission. Indeed, I believe that the Moon project conceived by the ISRO is both feasible and worthwhile. Roddam Narasimha

National Institute of Advanced Studies, Bangalore 560 012, India

\section{correspondence}

Contributions to Correspondence may be submitted to corres@nature.com. They should be no longer than 500 words, and ideally shorter. Published contributions are edited. 